\title{
Transcatheter closure of sinus of Valsalva aneurysm rupture in a young patient
}

\author{
Seçkin Satılmıș, Emrah Bozbeyoğlu, Gökhan Ertaș, Özlem Yıldırımtürk, Aydın Yııdırım
}

Department of Cardiology, Istanbul Dr. Siyami Ersek Thoracic and Cardiovascular Surgery Training and Research Hospital, Istanbul, Turkey

Postep Kardiol Inter 2013; 9, 4 (34): 390-391 DOI: $10.5114 /$ pwki.2013.38870

\section{A bstract}

Sinus of Valsalva aneurysm rupture is a rare cardiac anomaly and demands prompt treatment. We present a case of a young patient who underwent transcatheter closure due to a ruptured sinus of Valsalva aneurysm.

Key words: transcatheter closure, sinus Valsalva aneurysm.

\section{Image}

Aneurysm of sinus of Valsalva is rare and this type of aneurysm is typically congenital or acquired. It is usually in the right or noncoronary sinuses [1-3]. A 24-year-old patient was admitted to the outpatient clinic with dyspnea. Physical examination revealed a grade 4 continuous murmur. Transesophageal echocardiography (TEE) revealed a ruptured sinus of Valsalva aneurysm left-to-right shunt from the aorta into the right atrium and rheumatic aortic valve. The patient had high fevers and weakness 2 weeks ago.

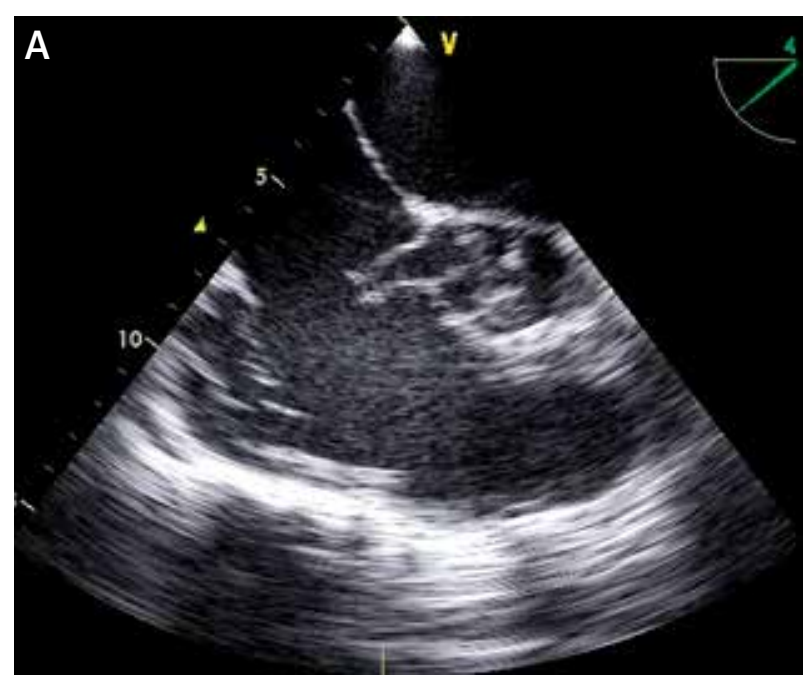

Sinus of Valsalva aneurysm might be ruptured due to infective endocarditis. Surgical repair is recommended in patients with ruptured sinus of Valsalva aneurysm, especially with intracardiac shunting. Our patient underwent a successful transcatheter closure of sinus of Valsalva aneurysm rupture procedure with a 12/14 $\mathrm{mm}$ PDA occluder device (Cardiofix, Starway Medical, Beijing China). Transesophageal echocardiography confirmed that the device was in a suitable position. Transcatheter closure of sinus of Valsalva aneurysm rupture is feasible, effective and safe.

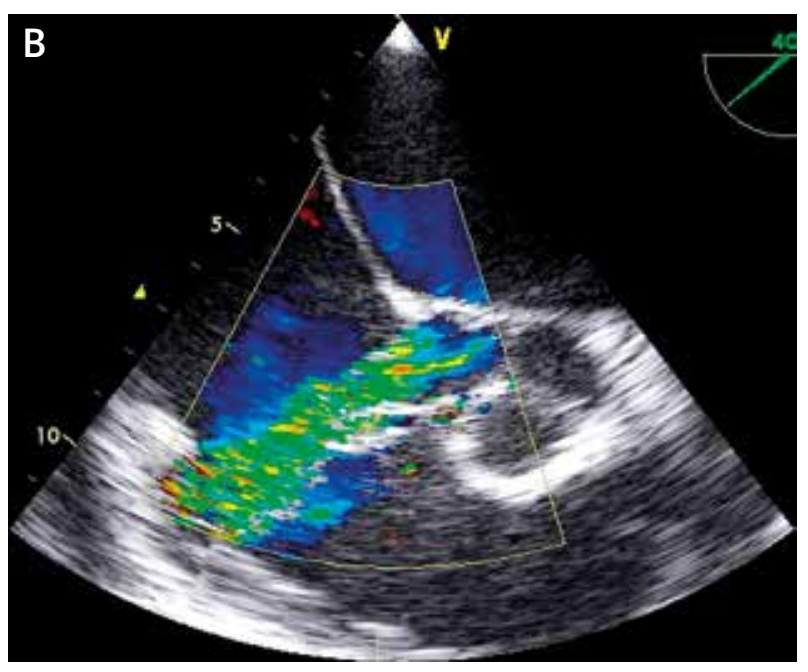

Fig. 1. Transesophageal echocardiography revealed a ruptured sinus of Valsalva aneurysm left-to-right shunt from the aorta into the right atrium (A, B)

\section{Corresponding author:}

Gökhan Ertaș, MD, Department of Cardiology, Istanbul Dr. Siyami Ersek Thoracic and Cardiovascular Surgery, Training and Research Hospital, Tıbbiye Street, Haydarpașa-Kadıköy 34710, Istanbul, Turkey, tel.: 0216418 9610, fax: 0216337 9719, e-mail: drgokhanertas@yahoo.com.tr Received: 2.05.2013, accepted: 10.10.2013. 

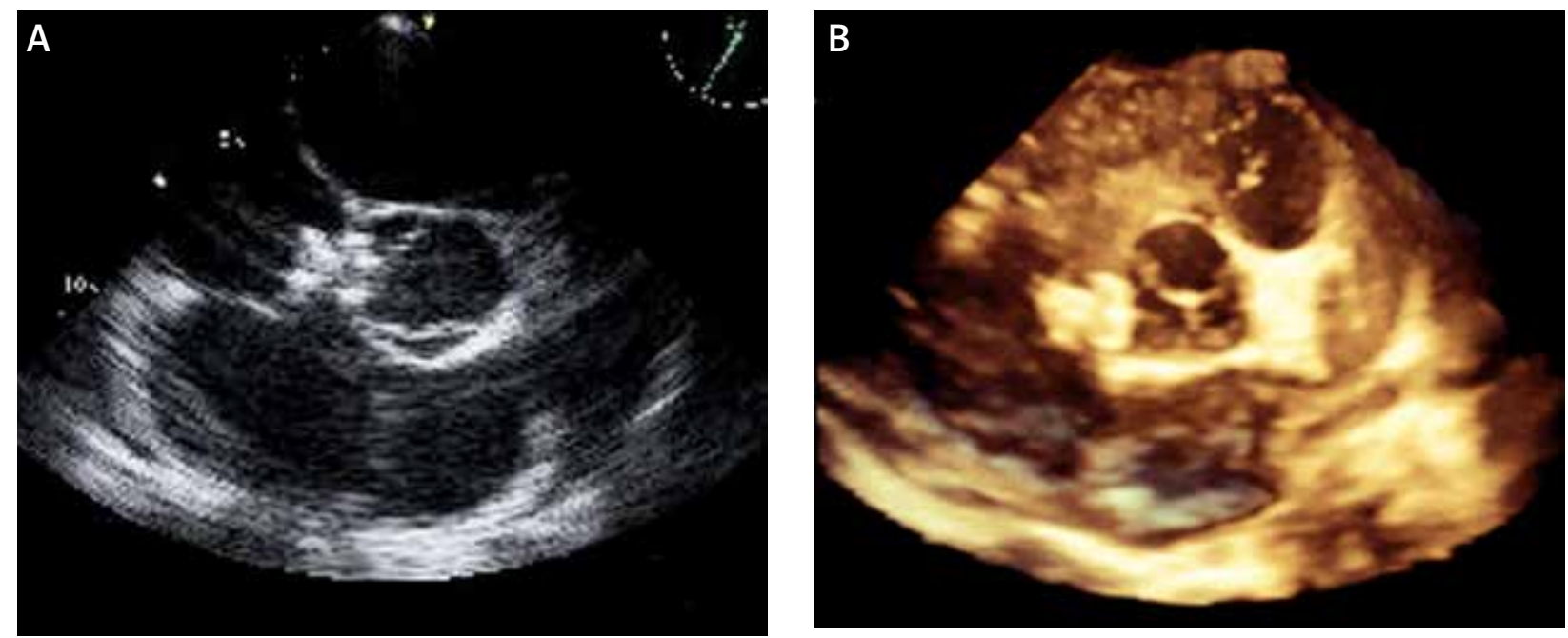

Fig. 2. Transesophageal echocardiography confirmed that the device was in a suitable position (A, B)

\section{References}

1. Ertaș G, Cetinkaya AS, Mehmetoğlu ME. Ruptured sinus of Valsalva aneurysm association with bicuspid aortic valve. Neth Heart J 2013; 21: 48-49.

2. Zhao SH, Yan CW, Zhu XY, et al. Transcatheter occlusion of the ruptured sinus of Valsalva aneurysm with an Amplatzer duct occluder. Int J Cardiol 2008; 129: 81-85.

3. Akdemir R, Yeter E, Kılıç $\mathrm{H}$, et al. Percutaneous closure of a ruptured right coronary sinus of Valsalva aneurysm. Turk Kardiyol Dern Ars 2012; 40: 447-450. 